\title{
An Equivalence of Moore's Paradox and Gödel's Incompleteness Sentence in Two-Valued Algebra of Formal Ethics
}

\author{
Vladimir Lobovikov \\ Ural Branch of the Academy of Sciences
}

\begin{abstract}
The paper submits surprising results of systematical investigating a formal-ethical aspect of conjoining Wittgenstein's, Moore's, Parmenides', Gödel's, and Łukasiewicz's ideas. A critique of Wittgenstein's critique of the natural language of ethics and of metaphysics results in submitting and elaborating a new paradigm of metaphysics as formal axiology (in particular, formal ethics). In result, the classical metaphysics and ethics of moral rigor are represented as two-valued algebraic systems of metaphysics and formal ethics respectively. By means of this algebraic model, all the well-known scandal-making metaphysical tenets of Parmenides are produced as translations of corresponding algebraic equations from the symbolic language to the natural one. At the level of submitted discrete mathematical model of formal axiology, Parmenides' metaphysical (formal-axiological) concepts “consistency" and "inconsistency," “completeness" and "incompleteness" are compared with Gödel's logic ones. Formal-axiological meanings of the words "consistency," "incompleteness," "being," "nonbeing," "movement," "knowledge," "belief," etc., are considered as moral-evaluation-functions determined by one moral-evaluation-variable. Binary moral-evaluation-functions are studied as well. The functions are precisely defined by tables. Precise definitions of "formal-axiological-equivalence," "formal-axiological-law," and "formal-axiological contradiction" are submitted. Thus, one can either generate or examine formal-axiological equations of algebra of metaphysics by "computing" relevant compositions of moral-value-functions. Using this "moral-value-table-computation-technique," one can arrive to a surprising conclusion that both the notorious sentence of Moore (called "epistemic paradox") and the incompleteness sentence of Gödel are formally-axiologically inconsistent ones: Hence, they are formally-axiologically equivalent. For overcoming the negative psychological effect of such a surprising result, the author has used graphic models explicating the famous Łukasiewicz's statement "Logic is morality of thought and speech."

Keywords: algebra-of-formal-ethics, moral-evaluation-function, formal-ethical-equivalence, knowledge, belief, formal-ethical-contradiction, incompleteness, consistency
\end{abstract}

Vladimir Lobovikov, Dr. Hab., full prof., principal researcher, Institute of Philosophy-and-Law, Ural Branch of Russian Academy of Sciences, Yekaterinburg, Russia; main research field: Inventing and Investigating Discrete Mathematical Models in the Humanities-Logic, Ethics, Aesthetics, Metaphysics, Philosophy of Language, Philosophy of Science, Philosophy of Law, Political Economy, and Philosophy of Religion. 


\section{Two Worlds, Two Languages, Two Semantics, Two Linguistic Principles of Compositionality, and Two Kinds of Nonsenses (Critical Analyzing Some Well-Known Ideas of Wittgenstein and of Moore from the Viewpoint of an Almost Unknown Two-Valued Algebraic System of Formal Ethics of Moral Rigor ${ }^{1}$}

George Moore's and Ludwig Wittgenstein's lives were interconnected: Sometimes they interfered into each other even paradoxically. According to the apocryphal stories, not only Moore evaluated Wittgenstein as a philosopher but also Wittgenstein evaluated Moore (as a philosopher). For instance, originally the name "Moore's paradox" was given by Wittgenstein who being extremely shocked by the paradoxical sentence of Moore proclaimed that this paradox was the main discovery of Moore in sphere of philosophy. The present paper begins with a critique of Wittgenstein's attitude to semantics of the natural language of ethics and of metaphysics. And only then I start talking about Moore's notorious sentence allegedly called "logic paradox."

Analyzing the linguistic philosophy of Wittgenstein $(1949 ; 1966 ; 1993)$ is implemented by means of a discrete mathematical simulation of the famous principle of logic separation of facts and contingent values. For precise formulating this principle, an artificial language of two-valued algebra of formal ethics is exploited. Being equipped with the (fact-\&-contingent-value)-separation principle, I submit systematical separating two worlds, two opposite aspects of natural languages, two formal semantics, two kinds of meanings, two different principles of linguistic compositionality of meanings, and two kinds of nonsenses. The twin worlds, twin aspects of natural languages, twin formal semantics, twin kinds of meanings, and twin kinds of nonsenses are inter-excluding and inter-complementing ones. The first elements of the twins are related to the world of "Tractatus" (Wittgenstein 1949). The second elements of the twins are related to the world of pure values (absolute ones) which world is transcendent to the one of "Tractatus." Beginning of this paper is targeted at explicating and precise tabular defining formal-axiological meanings of words and compound word-combinations of the natural language of morals and of metaphysics. I proclaim that according to a below-submitted (novel), formal-axiological principle of linguistic compositionality (of meanings), formal-axiological meaning of a compound word-combination (of the natural language of morals and of metaphysics) is a composition of such moral-evaluation-functions which are formal-axiological meanings of the parts of the compound word-combination. The idea of computing formal-axiological meanings of compound word-combinations (of the language of morals and of metaphysics) is exemplified by discussing proper-knowledge, alethic-faith, and alethic-tolerance (Lobovikov 2011a; 2011c; 2014c). In the algebraic system of formal ethics, a precise definition of the formal-ethical-equivalence relation among moral-evaluation-functions is given and formal-ethical equations are generated by means of computing relevant moral-evaluation-tables (Lobovikov 2007a; 2007b; 2014a; 2015b). Now let us start discussing Wittgenstein's ideas.

Quite naturally this paper is to irritate those who are funs of Wittgenstein and know his biography and writings very well. It is so because Wittgenstein used to write and speak about: the world but not (two) worlds; the language but not (two) languages; the nonsense but not (two) kinds of nonsenses. Hence, this paper is devoted not to creating a precise realistic picture of Wittgenstein's philosophy as such but to criticizing his worldview by means of discrete mathematical modeling a formal-ethical aspect of it. According to logic, methodology, and philosophy of science, it is normal that model and original do not coincide: They must be similar but not completely identical; otherwise, model has no heuristic value. Wittgenstein did not undertake 
discrete mathematical modeling a formal-ethical aspect of his worldview. He did not undertake a formal-ethical investigation as well. Sometimes he spoke and wrote of ethics but not of formal one. Moreover, he summoned and tried to avoid explicitly talking of (positive) ethics: His talks (and even the lecture) of ethics were negative: Positive talking of ethics (and of metaphysics) was labeled as meaningless. One can paradoxically characterize his "Tractatus logico-philosophicus" as a treatise about ethics but the "Tractatus" defines ethics only negatively and implicitly: It does not contain manifestly defining and substantiating positive moral values. Wittgenstein believed that proper moral values are to be shown in human conduct instead of being spoken about (as speaking of proper moral values has no meaning). Nevertheless, below I undertake investigating possibility of manifest (explicit) formulating a proper ethical system (formal-ethical one) of moral evaluations in spite of the well-established and recognized fact of flexibility and relativity of moral assessments of elementary moral actions. That is why funs and connoisseurs of Wittgenstein may be irritated by the below presented formal-ethical discourse. Notwithstanding this expectation, I believe that the below-submitted discourse is worth taking seriously and discussing systematically.

In times of Wittgenstein, the descriptive-indicative meanings of empirical sentences and the formal-logical semantics of the language of science were investigated carefully. On the contrary, the possibility of construction and systematical application of a formal-axiological semantics of evaluative sentences (of ethics, aesthetics, religion, metaphysics, etc.) was not recognized. (I think that it is not recognized properly even today.) Investigating the evaluative (formal-axiological) semantics of the natural language was underestimated and even ignored. Probably at the level of sub-consciousness, Wittgenstein perceived this asymmetry situation and therefore instinctively tried to correct it by attracting attention to semantics of the natural language which combined both aspects: the factual (organized by formal logic) and the evaluative (organized by formal axiology) ones.

According to Wittgenstein's "Tractatus," the world is a totality of facts (1949). Let the symbol $W_{l}$ stand for this world. Values do not belong to the world $W_{l}$. As "truth-values" are values Wittgenstein believes that "Logic is transcendental" (1949). Ethics, aesthetics, and other axiological disciplines are transcendental as well (Wittgenstein 1949). That language which is isomorphic to the world of "Tractatus" (let the language be called $L_{l}$ ) must be not used in any talks about pure values: Otherwise the talks become meaningless. Using the language $L_{1}$, one must abstain from saying something about pure values. Otherwise, using the language $L_{l}$ heads to nonsenses.

Nevertheless, as strange as it is, Wittgenstein himself was not perfectly silent with respect to values; he did not absolutely abstain from discussing them at the level of natural language. Many facts of his private life (Wittgenstein 1961), philosophical texts, and confessions of the people with whom he communicated demonstrate that he shared quite definite religious and moral values and norms, attempted to follow them systematically in his life (Deangelis 2007; Goldstein 1999; Hacker 1996; Jareño-Alarcón 2001; Malcolm 1993; Wittgenstein 1961; 1966; 1993; Wright 1982). Thus, he really lived in the world of values or at its border-line (let the world of values be called $W_{2}$ ). By definition, the world $W_{2}$ is a totality of values (and only values). Facts do not belong to $W_{2}$. The two worlds $W_{l}$ and $W_{2}$ exclude and complement each other ${ }^{2}$. Their union makes up the universe of discourse accomplished by means of the natural language. That language $\left(L_{l}\right)$, which is isomorphic to the world of "Tractatus," is an important subsystem of the natural language as a system. ${ }^{3}$ Another important subsystem of the natural language system is such a language (let it be called $L_{2}$ ), which is isomorphic to the world of pure values $\left(W_{2}\right) . L_{2}$ must be not used in any talks about pure facts: Otherwise, the 
talks become meaningless. Using only the language $L_{2}$, one must abstain from saying something about pure facts as such. Otherwise, the usage of $L_{2}$ heads to nonsenses.

There are two different kinds of nonsenses. One kind of them (let us call it $N_{l}$ ) is a result of using $L_{l}$ for talking about $W_{2}$. Another kind of nonsenses (let us call it $N_{2}$ ) is a result of using $L_{2}$ for talking about $W_{1}$. The relationship $<W_{1}, L_{1}>$ makes up the descriptive-indicative (formal-logical) semantics to be called $S_{l}$. The relationship $<W_{2}, L_{2}>$ makes up the evaluative (formal-axiological) semantics to be called $S_{2}$. As the first is well-studied and the second is almost unknown, hereafter we shall discuss systematically the formal-axiological semantics dealing with formal-axiological meanings (let $M_{2}$ stand for these meanings) of words and word-combinations of the natural language. (Let, respectively, $M_{l}$ stand for the descriptive-indicative meanings of the natural one.)

The present paper is aimed at explicating necessarily universal and immutable laws of the world of pure (absolute) values. However, many humans believe that absolute laws (strictly universal and perfectly immutable ones) of the world of pure values do not exist. The overwhelming majority believe that being of such formal-axiological laws is impossible as values and assessments are necessarily relative and undergo permanent change.

Many humans believe that any relativism is incompatible with objective knowledge. In particular, they think that if moral evaluations of concrete contents of moral actions (and agents) are relative to evaluators, then objective moral laws (=necessarily universal and immutable positive-moral-evaluations of actions) do not exist as they are impossible on principle. However, in my opinion, objective knowledge is compatible with some forms of relativism (Lobovikov 2014a; 2014c; 2015a; 2015b). For instance, it is compatible with a relative relativism, i.e., such relativism, which is not an absolute one.

This general statement may be exemplified by the relativistic physics. In the special-relativity-theory, it is demonstrated that (if $x$ is a physical body then) mass of $x$, length of $x$, time of $x$ are necessarily relative: They necessarily depend upon that physical systems, in relation to which they are measured; measuring in relation to different systems gives different results. Nevertheless, there are some physical qualities which invariantly exist in relation to all physical systems. These invariant physical qualities are considered as objective laws of the special-relativity-theory. Thus, physics has made a precedent to be applied to analogous cases. The situation in relativistic ethics is analogous to the one in relativistic physics. Therefore, the experience of creating relativistic physics is heuristically important for creating relativistic ethics as a system of objective knowledge of absolute laws of the moral-value-relativity.

The special-relativity-theory is precisely formulated and developed by means of the mathematical language. It is impossible to create and develop this theory by means of the natural language. In formal ethics, the situation is analogous to the one in physics. It is impossible to create and develop a theory of relativity of moral evaluations (as a system of absolute laws of their relativity) at the level of natural language. For departing from the old-fashioned absolute-moral-relativism to precise mathematical formulations of absolute formal-ethical laws of moral-evaluation-relativity (Lobovikov 2014a; 2014c; 2015a; 2015b), it is necessary to construct an artificial language of formal ethics for investigating a mathematical model of the system of moral evaluations of actions and agents. Hereafter let us start constructing the artificial language and the mathematical model.

Below the possibility of mathematical representation of moral activity is demonstrated by the elementary mathematical ethics - two-valued algebra of good and evil (Lobovikov 1999; 2007a; 2009a; 2011a; 2014a; 
2015b). This algebra is based upon the set D of either moral acts or moral agents (persons). By definition, moral acts are such and only such operations which are either-good-or-bad ones in the moral meaning of the words "good" and "bad." By definition, moral agents (persons) are such and only such agents (persons) which are either-good-or-bad ones in the moral meaning of the words "good" and "bad." Algebraic operations, defined on the set D, are moral-evaluation-functions. Moral-evaluation-variables of these functions take their values from the set $\{g, b\}$. Here the symbols " $g$ " and " $b$ " stand for the moral values (of elements of D) "good" and "bad" respectively. The functions take their values from the same set. The symbols " $x$ " and " $y$ " stand for moral-forms of acts-or-agents. Elementary moral-forms deprived of their contents are independent moral-evaluation-variables. Compound moral-forms deprived of their contents are moral-evaluation-functions determined by these variables.

Let symbol $\Sigma$ stand for the moral evaluator, i.e., that person, in relation to which all evaluations are generated. In the moral-evaluation-relativity theory, $\Sigma$ is a variable: Changing values of the variable $\Sigma$ can result in changing moral evaluations of concrete acts and agents. However, if a value of the variable $\Sigma$ is fixed, then moral evaluations of concrete acts and agents are definite.

DEFINITION DF-1 (of invariant law of moral-relativity theory): in two-valued algebra of formal ethics, a moral-evaluation-function is called formally-ethically (or invariantly) good one, if and only if it acquires the moral value $g$ (good) under any possible combination of moral values of its variables.

DEFINITION DF-2 (of formal-ethical contradiction): in two-valued algebra of formal ethics, a moral-evaluation-function is called formally-ethically (or invariantly) bad one, if and only if it acquires the moral value $b(\mathrm{bad})$ under any possible combination of moral values of its variables.

DEFINITION DF-3 (of formal-ethical-equivalence-relation): in two-valued algebra of formal ethics, moral-evaluation-functions $x$ and $y$ are formally-ethically equivalent (this is represented by the symbol " $x=+=y$ "), if and only if they acquire identical moral values (from the set $\{g, b\}$ ) under any possible combination of moral values of the variables. In the natural language, the equivalence relation " $x=+=y$ " is represented by the ambiguous word-homonym "is" (Lobovikov 2007b; 2015b). Its ambiguity and homonymy was noticed and recognized by many prominent logicians and philosophers including Wittgenstein $(1949,55)$. For adequately understanding the present paper, here it is worthy of note that "is" as the logical connective, and "is" as a linguistic means for representing the relation " $x=+=y$ " in the natural language, have significantly different meanings. Substituting them for each other is strictly forbidden. Violating this prohibition produces linguistic illusions of logic contradictions with facts.

Taking into an account the above-given definitions, one can make an important discovery: the invariant laws of moral-relativity theory do not depend upon changes of the moral evaluator $\Sigma$. If $x$ is a formal-ethical law, then $x$ is morally good in relation to every moral evaluator $\Sigma$.

Moreover, in the moral-relativity theory under review, formal-ethical contradictions of complex moral conduct also do not depend upon changes of the moral evaluator $\Sigma$. If $x$ is a formal-ethical contradiction, then $x$ is morally bad in relation to every moral evaluator $\Sigma$.

Finally, if there is the above-defined formal-ethical equivalence-relation between moral-evaluation-functions $x$ and $y$, then the functions $x$ and $y$ are formally-ethically equivalent ones in relation to every moral evaluator $\Sigma$. 
Hence, in spite of the flexibility and relativity of elementary moral evaluations, there are absolute invariants (immutable universal laws) of the moral relativity (Lobovikov 2014a; 2014c). Thus, the moral relativity is not absolute but relative one.

To exemplify the above-said, let us discuss moral-evaluation-functions "proper knowledge," "alethic (true) faith," "doubt," "assumption," "toleration," and "tolerance" in two-valued algebraic system of formal ethics. To begin discussing these functions, let us introduce the symbols standing for them in the artificial language of this algebra and then precisely define formal-axiological meanings of the introduced symbols by means of corresponding tables.

The glossary for the Table 1: The symbol $K^{E} x y$ stands for the moral-evaluation-function " $x$ 's knowing (what, whom) $y$ " (in the proper-episteme meaning of "knowing"). $A^{D} x y$-the evaluation-function " $x$ 's assuming $y$ (as a proper-episteme)." I $I^{D} x y$ - “x's not-assuming y (as a proper-episteme)." $N^{E} x y$ - "x's not-knowing (what, whom) $y$." $D^{X} x y$ - “y's being a doxa of/for $x$." $D^{M} x y$ - “ $y$ 's having a determined epistemic quality for $x$." The moral-evaluation-functional sense of these operations is defined by the Table 1 .

Table 1

"Proper-Episteme" and "Assumption"

\begin{tabular}{llllllll}
\hline$x$ & $y$ & $K^{E} x y$ & $A^{D} x y$ & $I^{D} x y$ & $N^{E} x y$ & $D^{X} x y$ & $D^{M} x y$ \\
\hline $\mathrm{g}$ & $\mathrm{g}$ & $\mathrm{b}$ & $\mathrm{g}$ & $\mathrm{b}$ & $\mathrm{g}$ & $\mathrm{g}$ & $\mathrm{b}$ \\
$\mathrm{g}$ & $\mathrm{b}$ & $\mathrm{b}$ & $\mathrm{g}$ & $\mathrm{b}$ & $\mathrm{g}$ & $\mathrm{g}$ & $\mathrm{b}$ \\
$\mathrm{b}$ & $\mathrm{g}$ & $\mathrm{g}$ & $\mathrm{g}$ & $\mathrm{b}$ & $\mathrm{b}$ & $\mathrm{b}$ & $\mathrm{g}$ \\
$\mathrm{b}$ & $\mathrm{b}$ & $\mathrm{b}$ & $\mathrm{b}$ & $\mathrm{g}$ & $\mathrm{g}$ & $\mathrm{b}$ & $\mathrm{g}$ \\
\hline
\end{tabular}

The glossary for the Table 2: The symbol $F^{4} x y$ stands for moral-evaluation-function "x's alethic (true) faith (not-revisable belief) in (what, whom) $y . " D^{N} x y$ - “x's alethic doubt (not-removable one) in not- $y . " F^{N} x y$ - “x's true faith (not-revisable belief) in not-y." $D^{T} x y$ - “x's alethic doubt (not-removable one) in $y . " S^{C} x y$ - “x's alethic (true) skepticism concerning $y$, i.e., $x$ 's alethic doubt in both: $y$ and not-y." $N^{S} x y$ - "nonbeing of $x$ 's alethic skepticism concerning $y$," i.e., "either $x$ 's alethic faith in $y$," or " $x$ 's alethic faith in not-y." The moral-evaluation-functional sense of these operations is defined by the Table 2 .

Table 2

"Alethic Faith" and "Alethic Doubt"

\begin{tabular}{llllllll}
\hline$x$ & $y$ & $F^{4} x y$ & $D^{N} x y$ & $F^{N} x y$ & $D^{T} x y$ & $S^{C} x y$ & $N^{S} x y$ \\
\hline $\mathrm{g}$ & $\mathrm{g}$ & $\mathrm{b}$ & $\mathrm{g}$ & $\mathrm{b}$ & $\mathrm{g}$ & $\mathrm{g}$ & $\mathrm{b}$ \\
$\mathrm{g}$ & $\mathrm{b}$ & $\mathrm{b}$ & $\mathrm{g}$ & $\mathrm{b}$ & $\mathrm{g}$ & $\mathrm{g}$ & $\mathrm{b}$ \\
$\mathrm{b}$ & $\mathrm{g}$ & $\mathrm{g}$ & $\mathrm{g}$ & $\mathrm{b}$ & $\mathrm{b}$ & $\mathrm{b}$ & $\mathrm{g}$ \\
$\mathrm{b}$ & $\mathrm{b}$ & $\mathrm{b}$ & $\mathrm{b}$ & $\mathrm{g}$ & $\mathrm{g}$ & $\mathrm{b}$ & $\mathrm{g}$ \\
\hline
\end{tabular}

The glossary for the Table 3: The symbol $N^{N} x y$ stands for " $x$ 's alethic (true) non-toleration of not- $y$," or " $x$ 's not-standing (what, whom) not- $y$." $T^{O} x y$ - “ $x$ 's alethic toleration of $y$," or " $x$ 's standing $y$." $N^{O} x y$ - " $x$ 's alethic non-toleration of $y . " T^{N} x y$ - " $x$ 's alethic toleration of not- $y$." $T^{C} x y$ - " $x$ 's alethic tolerance to $y$, i.e., $x$ 's standing both: $y$ and not- $y$." $N^{T} x y$ - "nonbeing of $x$ 's alethic tolerance to $y$," i.e., "either $x$ 's alethic non-toleration of $y$," or " $x$ 's alethic non-toleration of not- $y$." These operations are defined by the Table 3 . 
Table 3

"Toleration" and "Alethic Tolerance"

\begin{tabular}{llllllll}
\hline$x$ & $y$ & $N^{N} x y$ & $T^{O} x y$ & $N^{O} x y$ & $T^{N} x y$ & $T^{C} x y$ \\
\hline $\mathrm{g}$ & $\mathrm{g}$ & $\mathrm{b}$ & $\mathrm{g}$ & $\mathrm{b}$ & $\mathrm{g}$ & $\mathrm{g}$ & $\mathrm{b}$ \\
$\mathrm{g}$ & $\mathrm{b}$ & $\mathrm{b}$ & $\mathrm{g}$ & $\mathrm{b}$ & $\mathrm{g}$ & $\mathrm{g}$ & $\mathrm{b}$ \\
$\mathrm{b}$ & $\mathrm{g}$ & $\mathrm{g}$ & $\mathrm{g}$ & $\mathrm{b}$ & $\mathrm{b}$ & $\mathrm{b}$ & $\mathrm{b}$ \\
$\mathrm{b}$ & $\mathrm{b}$ & $\mathrm{b}$ & $\mathrm{b}$ & $\mathrm{g}$ & $\mathrm{g}$ & $\mathrm{b}$ & $\mathrm{g}$ \\
\hline
\end{tabular}

Using the above-given definitions, one can demonstrate the following equations.

(1) $K^{E} x y=+=B^{F} x y$ : proper knowledge is alethic faith.

(2) $B^{F} x y=+=K^{E} x y$ : alethic faith is proper knowledge.

(3) $A^{E} x y=+=D^{N} x y$ : assuming means doubting-in-the-contrary.

(4) $N^{A} x y=+=B^{N} x y$ : not-assuming is alethic faith-in-the-contrary.

(5) $N^{K} x y=+=D^{T} x y$ : non-being of proper knowledge means doubt, i.e., non-being of alethic faith.

(6) $D^{E} x y=+=S^{C} x y$ : proper knowledge-indifference is equivalent to alethic faith-indifference.

(7) $R^{E} x y=+=B^{P} x y$ : non-being of proper knowledge-indifference is equivalent to non-being of alethic faith-indifference.

According to these equations, the knowledge-modalities and the corresponding faith-ones are formally-ethically equivalent to each other. This outcome of mathematical modeling is surprising for those who are used to the opposition of "knowledge" and "faith," hence, they could estimate equations (1)-(7) as paradoxes. However, there are only illusions of paradoxes caused by the ambiguity of the natural language. For destroying such illusions of paradoxes in algebra of formal ethics, there is a formal principle of logic autonomy of corresponding facts and contingent values, which is precisely formulated as follows.

Let $\beta x$ stand for an act of informing (true or false affirming) that $x$ takes place in reality. Concerning the relationship between "=+=" and "logic equivalence," the principle in question may be formulated as the following rule (A\&B):

(A) From the truth of $x=+=y$, it does not follow logically that logic equivalence of $\beta x$ and $\beta y$ is true;

(B) From the truth of logic equivalence of $\beta x$ and $\beta y$, it does not follow logically that $x=+=y$ is true.

The illusion of paradox concerning equations (1)-(7) is destroyed by (A\&B). This illusion is a result of not-recognized "jumps" from formal-ethical equivalences of empirical (contingent) moral evaluations to formal-logical equivalences of facts (and back from the formal-logical equivalences of facts to the formal-ethical equivalences of empirical moral evaluations). In algebra of formal ethics, such bridging the gap between facts and contingent moral evaluations is strictly forbidden by (A\&B), which is an explication of important particular case of the general principle of mutual formal-logic autonomy of corresponding factual propositions and empirical moral evaluations. ${ }^{4}$ The rule (A\&B) can be universalized in the following way. Let us call this generalization "(Y\&Z);"

(Y) From $x=+=y$, it does not logically follow that $(\beta x \odot \beta y)$;

(Z) From $(\beta x \odot \beta y)$, it does not logically follow that $x=+=y$.

Here the symbol "๑)" stands for any element of the set of all binary formal logic operations.

As to the unary operations of algebra of formal ethics, the general principle of logic autonomy of mutually corresponding empirical-values and facts can be precisely formulated as the following rule (U\&Q):

(U) From $\beta @ x$, it does not logically follow that $\beta x$; 
(Q) From $\beta x$, it does not logically follow that $\beta @ x$.

Here the symbol “@” stands for any element of the set of all unary operations of algebra of formal ethics. Such an explication and formulation of the principle of formal logic autonomy of facts and contingent values was submitted by me in (2007b; 2015b).

Now taking into an account the above-said, let us consider the famous linguistic principle of semantic compositionality of meanings of compound word-combinations (Horwich 1997; Pagin 2003; Pelletier 1994; 2001; 2003; Werning, Hunzen, and Machery 2012). According to this compositionality principle, the semantic meaning of a complex phrase is a function determined by meanings of parts of the complex phrase. If meanings of parts of the complex phrase are functions determined by meanings of their parts, then the semantic meaning of the complex phrase under consideration is a composition of the functions. Here the terms "function" and "composition of functions" are used in their proper mathematical meanings.

According to algebra of metaphysics considered as algebra of formal axiology (Lobovikov 2007b), in particular as algebra of formal ethics, semantic meanings of words and word-combinations in the natural language of ethics and of metaphysics are nothing but evaluation-functions determined by a finite number of evaluation-variables (Lobovikov 2007a; 2007b; 2009a; 2009a; 2011d; 2014a; 2015a; 2015b). Semantic meanings of compound word-combinations in the natural language of ethics and of metaphysics are nothing but compositions of the evaluation-functions which are formal-axiological meanings of the parts of the compound word-combinations under consideration. (Here the terms "function" and "composition of functions" are used in their proper mathematical meanings as well.) It is easy to see that in the language $L_{2}$, the linguistic principle of semantic compositionality of meanings of compound word-combinations is a very specific one. Let this specific formal-axiological compositionality-principle be called $C-P_{2}$. Hence, respectively, the linguistic principle of semantic compositionality of meanings of compound word-combinations in the language $L_{1}$ is to be called $C-P_{1}$. The functions and compositions of functions implied by the two compositionality principles $\left(C-P_{1}\right.$ and $\left.C-P_{2}\right)$ are significantly different ones. How does the principle $C-P_{2}$ work? For showing a concrete example of its functioning, let us consider George Moore's epistemic paradox (Almeida 2001; Cholbi 2009; Green and Williams 2007; 2011; Heal 1994; Lobovikov 2014b). To do this, we need some additional moral-evaluation-functions to be introduced and defined by the below glossaries and tables.

The glossary for the Table 4: The symbol $K_{2} x y$ stands for the binary moral-evaluation-function "uniting (conjoining) $x$ and $y$ in a whole." (Here the index 2 indicates that the indexed letter stands for a binary operation.) $T_{2} x y$-the moral-evaluation-function "destruction, termination of $x$ by $y$." $P_{2} x y$-the evaluation-function "preservation, conservation of $x$ by $y$." $O_{2} x y$ - " $y$ 's offensive, assault (aggression) against $x$." $D_{2} x y$ - "defense of $x$ by $y$." $V_{2} x y$ - " $y$ 's violence over (whom) $x$." $J_{2} x y$ - " $y$ 's nonviolence over (whom) $x$." $U_{2} x y$ - "strong (excluding) moral choice of the best between $x$ and $y$ (implying realization of the chosen and non-realization of the not-chosen)." $A_{2} x y$ - "weak (not-excluding) moral choice (and realization) of the best among such moral alternatives which can be made up by means of $x$ and $y$ " (here possibility of choice and realization of $K_{2} x y$ is not excluded). $W_{2} x y$ - "uniting non-realization of $x$ and non-realization of $y$." $E_{2} x y$ - "moral identification of $x$ and $y$," or "morally equalizing $x$ and $y$." $C_{2} x y$ - "realizing $y$ in response to realization of $x$." $X_{2} x y$ - " $y$ 's contradiction to (whom) $x$." 
Table 4

Binary Moral Operations in Two-Valued Algebra of Formal Ethics

\begin{tabular}{|c|c|c|c|c|c|c|c|c|c|c|c|c|c|c|}
\hline$x$ & $y$ & $K_{2} x y$ & $T_{2} x y$ & $P_{2} x y$ & $\mathrm{O}_{2} x y$ & $D_{2} x y$ & $V_{2} x y$ & $J_{2} x y$ & $U_{2} x y$ & $A_{2} x y$ & $W_{2} x y$ & $E_{2} x y$ & $C_{2} x y$ & $X_{2} x y$ \\
\hline $\mathrm{g}$ & $\mathrm{g}$ & $\mathrm{g}$ & $\mathrm{b}$ & $\mathrm{g}$ & $\mathrm{b}$ & $\mathrm{g}$ & $\mathrm{b}$ & $\mathrm{g}$ & $\mathrm{b}$ & $\mathrm{g}$ & $\mathrm{b}$ & $\mathrm{g}$ & $\mathrm{g}$ & $\mathrm{b}$ \\
\hline g & $\mathrm{b}$ & $\mathrm{b}$ & $\mathrm{b}$ & g & $\mathrm{b}$ & g & $\mathrm{b}$ & $\mathrm{g}$ & g & g & $\mathrm{b}$ & $\mathrm{b}$ & b & $\mathrm{b}$ \\
\hline b & g & $\mathrm{b}$ & $\mathrm{g}$ & $\mathrm{b}$ & g & $\mathrm{b}$ & g & $\mathrm{b}$ & $\mathrm{g}$ & $\mathrm{g}$ & $\mathrm{b}$ & $\mathrm{b}$ & $\mathrm{g}$ & $\mathrm{g}$ \\
\hline $\mathrm{b}$ & $\mathrm{b}$ & $\mathrm{b}$ & $\mathrm{b}$ & g & $\mathrm{b}$ & g & $\mathrm{b}$ & $\mathrm{g}$ & $\mathrm{b}$ & $\mathrm{b}$ & g & $\mathrm{g}$ & g & $\mathrm{b}$ \\
\hline
\end{tabular}

The glossary for the Table 5: The symbol Nx stands for the unary moral-evaluation-function "nonbeing of $x$." $B x$ - the moral-evaluation-function "being of $x$." Gx-"(monotheistic) God of $x$." Fx- "faith in $x$." Lx — "alethic necessity of $x . " M x$ — "movement (change) of $x$." Yx — "alethic accidentalness of x." Ox- "oneness (unity) of $x$," or " $x$ 's being one." $P x$ - “ $x$ 's being permitted." Ix-“deontic indifference to (what) $x$." $Z x$ - "alethic tolerance to (what) $x$." $S x$ - " $x$ 's self-destruction, self-termination (suicide)." $C x$ - " $x$ 's self-preservation, self-conservation, self-defense." Jx_- $x$ 's consistency," or "nonbeing of contradiction in $x$." $D x$ — “ $x$ 's divisibility, or dividedness, many-ness $x$." Xx- “ $x$ 's formal-axiological self-contradiction." Wx- " $x$ 's inconsistency or being of contradiction in $x$." Vx- "void of $x$." Ex-“completeness of $x$." Ux- $x$ 's incompleteness."

Table 5

Unary Moral Operations in Two-Valued Algebra of Formal Ethics

\begin{tabular}{lllllllllllllllllllll}
\hline$x$ & $N x$ & $B x$ & $G x$ & $F x$ & $L x$ & $M x$ & $Y x$ & $O x$ & $P x$ & $I x$ & $Z x$ & $S x$ & $C x$ & $J x$ & $D x$ & $X x$ & $W x$ & $V x$ & $E x$ & $U x$ \\
\hline $\mathrm{g}$ & $\mathrm{b}$ & $\mathrm{g}$ & $\mathrm{g}$ & $\mathrm{g}$ & $\mathrm{g}$ & $\mathrm{b}$ & $\mathrm{b}$ & $\mathrm{g}$ & $\mathrm{g}$ & $\mathrm{b}$ & $\mathrm{b}$ & $\mathrm{b}$ & $\mathrm{g}$ & $\mathrm{g}$ & $\mathrm{b}$ & $\mathrm{b}$ & $\mathrm{b}$ & $\mathrm{b}$ & $\mathrm{g}$ & $\mathrm{b}$ \\
$\mathrm{b}$ & $\mathrm{g}$ & $\mathrm{b}$ & $\mathrm{g}$ & $\mathrm{b}$ & $\mathrm{b}$ & $\mathrm{g}$ & $\mathrm{b}$ & $\mathrm{b}$ & $\mathrm{b}$ & $\mathrm{b}$ & $\mathrm{b}$ & $\mathrm{b}$ & $\mathrm{g}$ & $\mathrm{b}$ & $\mathrm{g}$ & $\mathrm{b}$ & $\mathrm{g}$ & $\mathrm{g}$ & $\mathrm{b}$ & $\mathrm{g}$ \\
\hline
\end{tabular}

Using the above-given definitions, one can substantiate the following equation of two-valued algebra of formal ethics.

(8) $K_{2} K^{E} x y N B^{F} x y=+=$ b.

According to DF-2 and DF-3, this equation means that Moore's paradox is a formal-ethical self-contradiction of x's activity (Lobovikov 2014b; 2014c). This is interesting in a wide philosophical context, but here I concentrate attention mainly on the fact that substantiating the equation (8) necessarily exploits the above-discussed principle of compositionality of formal-axiological meanings $\left(\mathrm{C}-\mathrm{P}_{2}\right)$.

Moreover, demonstrations of the following formal-ethical equations also imply using the formal-axiological compositionality principle $\left(\mathrm{C}_{-} \mathrm{P}_{2}\right)$.

(9) $C_{2} P S x P y=+=\mathrm{g}$ : if suicide is permitted, then everything is permitted (Wittgenstein 1961).

(10) $C_{2} N P d N P S x=+=\mathrm{g}$ : if some $d$ is not permitted, then suicide is not permitted (Wittgenstein 1961).

(11) $C_{2} N G x P y=+=\mathrm{g}$ : if God does not exist, then everything is permitted (attributed to Dostoyevsky ${ }^{5}$ ).

(12) $C_{2} N P d B G x=+=\mathrm{g}$ : if some $d$ is not permitted, then God exists (the contraposition of the equation (11).

(13) $N F G x=+=S x$ : nonbeing of trust in God of $x$ is $x$ 's self-destruction, self-termination (suicide).

(14) $F N G x=+=X x=+=$ b: faith in nonbeing of God of $x$ is $x$ 's formal-axiological self-contradiction.

The conjunction of the premise "some $d$ is not permitted" with the above equation (12) (obtained by the contraposition of the equation (11) logically implies the corollary "God exists" (by modus ponens). Thus, the discrete mathematical models of moral and metaphysical principles considered in this paper are interesting not only from abstract-philosophy-theory viewpoints, but also from the ones of theology, ethics, 
jurisprudence, criminology, psychology, psychiatry. The practice aimed at preventing suicides unites all the mentioned disciplines in one activity and necessarily links them with the abstract fundamental investigation undertaken in this paper.

\section{Some Parmenides's and Zeno's Paradoxical Sentences and Gödel's Hope-Breaking Ones from the Viewpoint of Two-Valued Algebraic System of Metaphysics as Formal Ethics}

In my publications submitting and investigating the hypothesis that, in its essence, metaphysics is nothing but formal axiology in general (and formal ethics in particular), the following formal-axiological equations of the above-defined algebra are demonstrated and discussed (2007b).

(15) $B x=+=B x$ : being is being, or "being does exist" (Parmenides).

(16) $N x=+=N x$ : nonbeing is nonbeing, or "nonbeing does not exist" (Parmenides).

(17) $B x=+=O x$ : being is oneness, or "one does exist" (Parmenides).

(18) $D x=+=N x$ : many-ness is nonbeing, or "many-ness does not exist" (Parmenides).

(19) $M x=+=N x$ : movement is nonbeing, or "movement does not exist" (Parmenides).

(20) $M x=+=W x: x$ 's movement is being of contradiction in $x$ (Parmenides, Zeno).

(21) $B x=+=J x$ : $x$ 's being is nonbeing of contradiction in $x$ (Parmenides, Zeno).

(22) $B x=+=N M x$ : $x$ 's being is nonbeing of $x$ 's movement (Parmenides, Zeno).

(23) $V x=+=N x$ : void is nonbeing or "void does not exist."

(24) $B x=+=N V x$ : being is nonbeing of void.

(25) $U x=+=V x$ : incompleteness is void.

(26) $B x=+=E x=+=N U x$ : being is completeness or "being is complete."

(27) $B x=+=J x$ : being is consistency (non-contradictoriness), or "being is consistent."

This equation list makes up a discrete mathematical model of the Eleates' metaphysics (Guthrie 1990). From the above equations, it is easy to derive the following three ones.

(28) $J x=+=E x=+=N U x$ : consistency is equivalent to completeness!

(29) $U x=+=W x=+=N J x$ : incompleteness is equivalent to inconsistency!

(30) $B x=+=K_{2} J x E x$ : being is conjoining consistency and completeness!

These equations are very important in relation to proving the main statement of this paper because it is easy to transform them into the following one.

(31) $K_{2} J x U x=+=K_{2} J x N J x=+=K_{2} U x N U x=+=X x=+=b$; conjoining $x$ 's consistency with $x$ 's incompleteness is formally-axiologically inconsistent (self-contradictory) activity!

Consequently, if the consistent formal arithmetic theory S (investigated by K. Gödel) is a value of the variable $x$, then $\mathrm{S}$ is formally-axiologically inconsistent! One can be irritated by this discourse but the demonstration is logical; hence, the only option for rejecting the irritating corollary is rejecting the premises (initial definitions). But this does not undermine the paper's main statement which is conditional one: Rejecting some of the initial definitions makes the conditional statement true by making its antecedent false.

Nevertheless, feeling of logic-contradiction between the above equations (28)-(30) and Gödel's incompleteness theorems is strong and arises quite naturally. Therefore, here it is indispensable to make the following remark. The logic-contradiction impression is nothing but an illusion naturally produced by 
the ambiguity of natural language, namely, by the above-mentioned homonymy of the words "is" and "equivalence."

The above-given formulation of the principle of formal-logic independence of corresponding facts and contingent values is an effective remedy for illusions of this type. However, above the indicated principle of formal-logic independence of corresponding contingent moral evaluations and factual propositions is formulated too abstractly: No instantiation is submitted. Therefore, now I am to instantiate the mentioned principle and then to demonstrate how it works concerning the illusion of contradiction we are puzzled by. First of all, it is psychologically necessary and pedagogically reasonable to show an example of applying the principle under instantiation to a concrete situation of life of laymen equipped with common sense.

Let $\left(\mathrm{t}<+20^{\circ} \mathrm{C}\right)$ stand for the moral-action-form " $x$ 's body-temperature is made less than 20 degrees above zero centigrade." And let $\left(\mathrm{t}>+60^{\circ} \mathrm{C}\right)$ stand for the moral-action-form " $x$ 's body-temperature is made more than 60 degrees above zero centigrade." If the concrete circumstances of the situation are quite determined and the variables $x$ and $\Sigma$ are fixed, then the moral-action-forms $\left(\mathrm{t}<+20^{\circ} \mathrm{C}\right)$ and $\left(\mathrm{t}>+60^{\circ} \mathrm{C}\right)$ become moral actions which are either good or bad from the viewpoint of the evaluator $\Sigma$. In the two-valued algebra of formal ethics of moral rigor, for any $x$ and $\Sigma$, it is true that $\left(\left(\mathrm{t}<+20^{\circ} \mathrm{C}\right)=+=\left(\mathrm{t}>+60^{\circ} \mathrm{C}\right)\right)$. This formal-axiological equation deals with empirical moral-legal values exclusively: It has no formal-logic-entailment relations to corresponding statements of facts. According to the above formulation of the principle under exemplification, $\beta\left(\mathrm{t}<+20^{\circ} \mathrm{C}\right)$ stands for the fact-fixing-proposition " $x$ 's body-temperature is made less than 20 degrees above zero centigrade," and $\beta\left(\mathrm{t}>+60^{\circ} \mathrm{C}\right)$ stands for the fact-fixing-proposition " $x$ 's body-temperature is made more than 60 degrees above zero centigrade." Being propositions about facts, $\beta\left(\mathrm{t}<+20^{\circ} \mathrm{C}\right)$ and $\beta\left(\mathrm{t}>+60^{\circ} \mathrm{C}\right)$ are either true or false ones. Hence, it is quite natural to connect these two fact-fixing-propositions by the logic operation " $\leftrightarrow$ " (logic equivalence). The proposition $\left(\beta\left(\mathrm{t}<+20^{\circ} \mathrm{C}\right) \leftrightarrow \beta\left(\mathrm{t}>+60^{\circ} \mathrm{C}\right)\right)$ is nothing but logic connection of facts: It has nothing to do with moral values. According to the above rule, if one implements the following "logic inference," the one commits the blunder, as there is no logic-consequence-relation between the "premise" and the "corollary."

$$
\frac{\left(\left(\mathrm{t}<+20^{\circ} \mathrm{C}\right)=+=\left(\mathrm{t}>+60^{\circ} \mathrm{C}\right)\right)}{\left.\beta\left(\mathrm{t}<+20^{\circ} \mathrm{C}\right) \leftrightarrow \beta\left(\mathrm{t}>+60^{\circ} \mathrm{C}\right)\right)}
$$

Here committing the jump from the alleged premise to the alleged corollary is strictly forbidden by the rule A. Violating this rule can result in a logic catastrophe: deriving evidently false purely factual "conclusion" from obviously true empirical-moral-evaluation "premise." Also the rule strictly prohibits the converse jump from the evident falsity of $\left(\beta\left(\mathrm{t}<+20^{\circ} \mathrm{C}\right) \leftrightarrow \beta\left(\mathrm{t}>+60^{\circ} \mathrm{C}\right)\right)$ to falsity of $\left(\left(\mathrm{t}<+20^{\circ} \mathrm{C}\right)=+=\left(\mathrm{t}>+60^{\circ} \mathrm{C}\right)\right)$ by "modus tollens" as there is no logic entailment relation between the two substantially different equivalences. Thus, the abstract rule is exemplified at the level of grass-roots.

Now let us go to the more abstract (metaphysical) situation of the Eleates' "paradoxes." Let us consider the above-given formal-axiological equation (19) $M x=+=N x$ : Movement is nonbeing or "movement does not exist." Intentionally violating the rule under instantiation, one can construct the following invalid argument underlying the "paradox" of Parmenides and Zeno.

$M x=+=N x$ : $x$ 's movement is (formally-axiologically equivalent to) $x$ 's nonbeing.

$(\beta(M x) \leftrightarrow \beta(N x))$ : affirming fact of $x$ 's movement is (formally-logically equivalent to) affirming fact of $x$ 's nonbeing.

At the level of natural language, the invalidity of this argument is hidden by the above-mentioned homonymy of the word "is." In the "premise," the word "is" stands for the axiological equivalence "=+=" 
but in the "corollary," the word "is" stands for the logical equivalence " $\leftrightarrow$." The "premise" $M x=+=N x$ is true but the "corollary" $(\beta(M x) \leftrightarrow \beta(N x))$ is false as from the experience viewpoint it is an absurd that " $x$ moves" if and only if " $x$ does not exist." Thus, humans were puzzled by the Eleates" "paradoxes." But using the "modus tollens" here for constructing the logic inconsistency under discussion is irrelevant as there is no logical consequence relation between the "premise" and the "corollary." Thus, the abstract rule under consideration is instantiated again (now at a more sophisticated level).

However, the above two quite impressive exemplifications are far away from the paper theme. Therefore, below such an instantiation is given which is just about the above-mentioned problem of impression of "logical contradiction" between Gödel's incompleteness theorems and formal-axiological equations (28)-(30) proved in two-valued algebra of metaphysics. Let the above true formal-axiological equations (28)-(29) are used as allegedly premises of the following invalid arguments (forbidden by the rule A).

$\begin{array}{ll}J x=+=N U x & U x=+=N J x \\ (\beta(J x) \leftrightarrow \beta(N U x)) & (\beta(U x) \leftrightarrow \beta(N J x))\end{array}$

Here at the level of natural language, the defectiveness of the arguments is quite masked by the ambiguity of the word-homonym "equivalence." In the "premises," the word "equivalence" stands for the axiological equivalence "=+=" but in the "corollaries," the word "equivalence" stands for the logic equivalence " $\leftrightarrow$." The "premise" $J x=+=N U x$ is true according to the above-formulated algebra of metaphysics (as formal axiology) but the "corollary" $(\beta(J x) \leftrightarrow \beta(N U x))$ is false according to the theorems of Gödel. However, using the "modus tollens" here for constructing the logic contradiction is irrelevant as there is no logical-consequence relation between the "premise" and the "corollary." Thus, the abstract rule under consideration is instantiated in relation to the concrete theme of this paper.

\section{A Meta-theoretical Interpretation of the Logical Square and Hexagon. A Metaphysical Dogma "Crashed" by the Hope-Breaking Gödel's Incompleteness Theorems}

The traditional logic exploits the square of opposition of the A, E, I, O (Béziau and Read 2014; Correia 2009; 2012). In XX century, A. Sesmat (1951) and R. Blanché (1957; 1966; 1969) had generalized the intellectual (heuristic and didactic) role of the square substantially by transforming it into a hexagon of opposition interpreted as a graphic model of universal conceptual scheme. After Sesmat (1951) and Blanché (1957; 1966; 1969), this promising trend in logic investigations was creatively developed by J.-Y. Béziau (2012a; 2012b). To the present time within the framework of this scientific-work-direction, a lot of interesting examples of graphic modeling knowledge systems (and thus organizing them) by means of logical hexagons were either discovered or invented (Sesmat 1951; Blanché 1957; 1966; 1969; Kalinowski 1972; Béziau 2012a; 2012b; Dufatanye 2012; Moretti 2012).

In addition to the rich collection of nontraditional interpretations of the logical square and hexagon, I have submitted a substantially new interpretation of the ones (Lobovikov 2015c): They are considered as meta-theoretical ones organizing logical interconnections among the meta-theoretic concepts "inconsistent," "consistent," "incomplete," "complete," "consistent and complete," and "if consistent, then incomplete" in a system of meta-theoretical knowledge.

Let the symbol "t" stand for a theory based on the classical logic exclusively. Let the symbol INCONS (t) stand for the meta-theoretic statement " $t$ is logically inconsistent." The symbol CONS (t) stands for the 
meta-theoretic statement " $\mathrm{t}$ is logically consistent." COMP ( $\mathrm{t}$ ) stands for the statement " $\mathrm{t}$ is logically (semantically) complete." INCOMP (t) stands for the statement "t is logically (semantically) incomplete." (CONS (t) $\supset \operatorname{INCOMP}(\mathrm{t})$ ) stands for the statement "if $t$ is consistent, then $t$ is incomplete." (COMP ( $t$ ) \& CONS ( $t)$ ) stands for the statement " $t$ is consistent and complete." In this part of the paper, I submit a new and somewhat nontrivial thesis that if only classical logic is meant, then the above mentioned meta-theoretic statements make up the below-given logical square and hexagon. Here the condition of classicalness of logic is important one as in some non-classical logics, for instance, in paraconsistent ones (Béziau 1999; Costa 1974; Costa, Krause, and Bueno 2007) the inconsistency does not logically imply the completeness. Nevertheless for any theories organized by the classical logic, the below square and hexagon are valid.

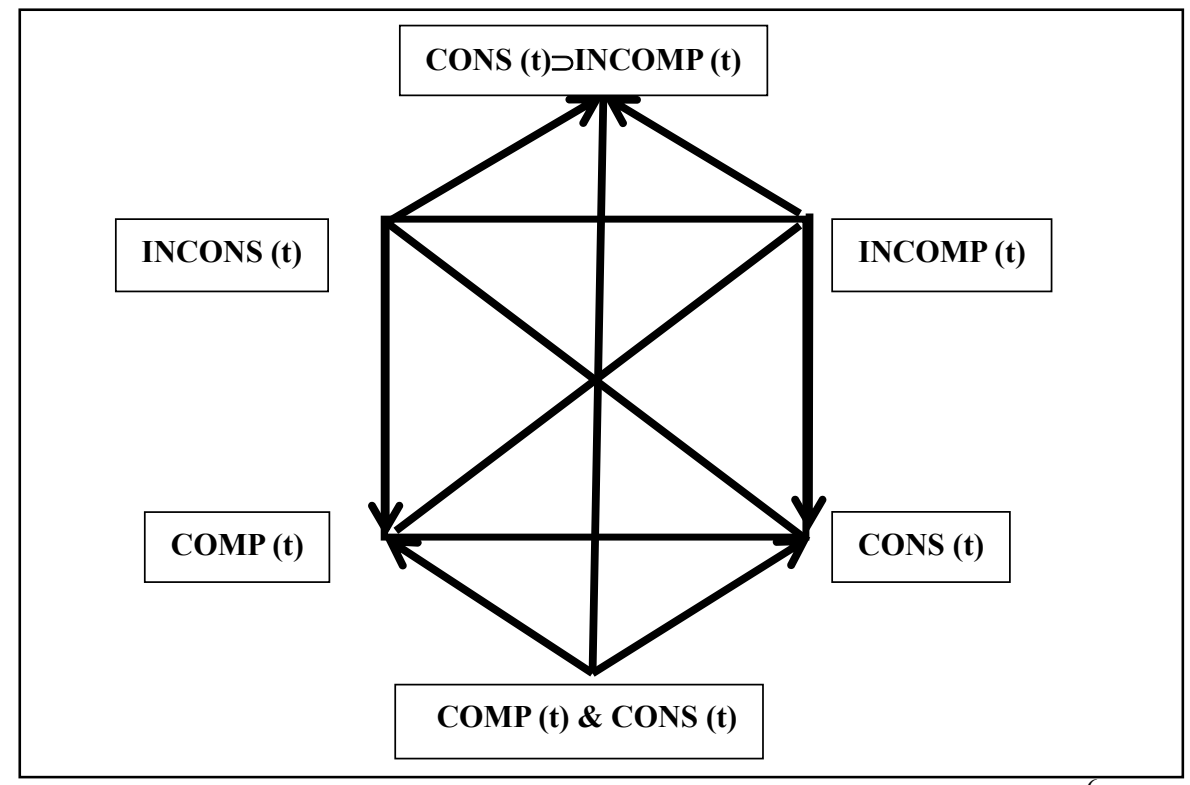

Fig. 1. The logical square-and-hexagon of the meta-theoretical statements. ${ }^{6}$

In this graphic model, the relations of logical contradiction (contradictory-ness) are represented by the lines crossing the square. The relations of logical subordination (logical consequence) are represented in the picture by the arrows. The relation of logical contrariety (contrary-ness) is represented by the upper horizontal line of the square. The relation of logical sub-contrariety (sub-contrary-ness) is represented by the lower horizontal line of the square.

This square-and-hexagon graphically represents the knowledge of several famous meta-theorems as a logically organized system. According to this graphic model, the first-order-predicate-logic and the propositional one belong to the set of theories to be placed at the bottom (lower corner) of the hexagon. On the contrary, the formal arithmetic theory S (investigated by Gödel) belongs to the set of theories to be placed at the top (upper corner) of the hexagon.

Obviously, in the times of Aristotle, Leibniz, and Cant, it was impossible to create the above-presented meta-theoretical interpretation of the square-and-hexagon of opposition as the empirical basis for such creation did not exist in their times: The relevant meta-theorems had not been proved yet. The set of proofs of meta-theorems necessary and sufficient for making up the empirical basis of the above-submitted meta-theoretical interpretation of the square-and-hexagon appeared only in XX century. 
In my opinion, the above logical hexagon may be interpreted as the one of opposition of a-priori theories and empirical (a-posteriori) ones. In this hypothetic interpretation, a-priori theories are defined as such and only such ones which are consistent and (semantically) complete. Graphically speaking, a-priori theories are located at the bottom (lower corner) of the above hexagon. In this respect, a-posteriori theories are defined as such and only such ones which are either inconsistent or (semantically) incomplete. Graphically speaking, a-posteriori theories are located at the top (upper corner) of the above hexagon. For instance, if the hexagon is interpreted as the one of opposition of a-priori and a-posteriori theories, then the first-order-predicate-logic theory and the propositional one are to be placed at the lower corner as they are consistent and complete and hence belong to the set of a-priori theories. In this interpretation of the hexagon, the formal arithmetic theory $\mathrm{S}$ (investigated by Gödel) is to be placed at the upper corner as, according to Gödel's incompleteness theorems, if S is logically consistent, then $\mathrm{S}$ is semantically incomplete. Hence, according to the definition of the notion "a-posteriori theory" accepted in the hypothetic interpretation of hexagon, the theory $\mathrm{S}$ belongs to the set of a-posteriori ones.

In my paper (2011d) devoted to discrete mathematical modeling the formal ethics of thought and speech, the epistemic modalities "provability of (what) $y$ for (what, whom) $x$ " and "truth or truthfulness of (what) $y$ for (what, whom) $x$ " (or " $y$ 's being true for $x$ ") are precisely defined and systematically investigated as moral-evaluation-functions determined by moral-evaluation-variables. In two-valued algebra of formal ethics of moral rigor, these epistemic-modality-functions are precisely defined by the following tables.

The glossary for the Table 6: The symbol $P^{R} x y$ stands for the moral-evaluation-function "provability (existence of proof) of (what) $y$ for/to (what, whom) $x . " N^{R} x y$ stands for the moral-evaluation-function "irrefutability of (what) $y$ for/to (what, whom) $x . " R^{F} x y$ - "refutability (existence of refutation) of (what) $y$ for/to (what, whom) $x . " N^{P} x y$ - "improvability (nonbeing of proof) of (what) $y$ for/to (what, whom) $x . "$ $I^{P} x y$ - "nonbeing of proof and nonbeing of refutation of (what) $y$ for/to (what, whom) $x$ " or "improvability and irrefutability of (what) $y$ for/to (what, whom) $x$." $D^{P} x y$ - "either being of proof or being of refutation of (what) $y$ for/to (what, whom) $x$ " or "either provability or refutability of (what) $y$ for/to (what, whom) $x$." The mentioned moral-evaluation-functions are defined by the Table 6 .

Table 6

"Proving" and "Refuting" as Moral Operations

\begin{tabular}{llllllll}
\hline$x$ & $y$ & $P^{R} x y$ & $N^{R} x y$ & $R^{F} x y$ & $N^{P} x y$ & $I^{P} x y$ & $D^{P} x y$ \\
\hline $\mathrm{g}$ & $\mathrm{g}$ & $\mathrm{b}$ & $\mathrm{g}$ & $\mathrm{b}$ & $\mathrm{g}$ & $\mathrm{g}$ & $\mathrm{b}$ \\
$\mathrm{g}$ & $\mathrm{b}$ & $\mathrm{b}$ & $\mathrm{g}$ & $\mathrm{b}$ & $\mathrm{g}$ & $\mathrm{g}$ & $\mathrm{b}$ \\
$\mathrm{b}$ & $\mathrm{g}$ & $\mathrm{g}$ & $\mathrm{g}$ & $\mathrm{b}$ & $\mathrm{b}$ & $\mathrm{b}$ & $\mathrm{g}$ \\
$\mathrm{b}$ & $\mathrm{b}$ & $\mathrm{b}$ & $\mathrm{b}$ & $\mathrm{g}$ & $\mathrm{g}$ & $\mathrm{b}$ & $\mathrm{g}$ \\
\hline
\end{tabular}

The glossary for the Table 7: The symbol $T^{R} x y$ stands for the moral-value-function " $y$ is a truth for (what, whom) $x$ " or " $y$ is true for $x$." The symbol $N^{F} x y$ stands for " $y$ is not-false for $x . " F^{4} x y$ - $y$ is false for $x$." $N^{T} x y$ - $y$ is not-true for $x "$ or " $y$ is not a truth for $x . " I^{T} x y$ - " $y$ 's truth-value-indifference, or truth-value-neutrality, $\quad$ or truth-value-indefiniteness for (what, whom) $\quad x . " \quad D^{T} x y$ - “ $y$ 's truth-value-non-indifference, or truth-value-non-neutrality, or truth-value-definiteness for $x$." These moral-value-functions are defined by the Table 7 . 
Table 7

"Truth" and "Lie" as Moral-Value-Functions

\begin{tabular}{llllllll}
\hline$x$ & $y$ & $T^{R} x y$ & $N^{F} x y$ & $F^{A} x y$ & $N^{T} x y$ & $I^{T} x y$ & $D^{T} x y$ \\
\hline $\mathrm{g}$ & $\mathrm{g}$ & $\mathrm{b}$ & $\mathrm{g}$ & $\mathrm{b}$ & $\mathrm{g}$ & $\mathrm{g}$ & $\mathrm{b}$ \\
$\mathrm{g}$ & $\mathrm{b}$ & $\mathrm{b}$ & $\mathrm{g}$ & $\mathrm{b}$ & $\mathrm{g}$ & $\mathrm{g}$ & $\mathrm{b}$ \\
$\mathrm{b}$ & $\mathrm{g}$ & $\mathrm{g}$ & $\mathrm{g}$ & $\mathrm{b}$ & $\mathrm{b}$ & $\mathrm{b}$ & $\mathrm{g}$ \\
$\mathrm{b}$ & $\mathrm{b}$ & $\mathrm{b}$ & $\mathrm{b}$ & $\mathrm{g}$ & $\mathrm{g}$ & $\mathrm{b}$ & $\mathrm{g}$ \\
\hline
\end{tabular}

Using the above-given definitions one can substantiate the following equation of two-valued algebra of formal ethics.

(32) $K_{2} T^{R} x y N P^{R} x y=+=$ b.

According to the above definitions $D F-2$ and $D F-3$, this formal-ethical equation means that the first incompleteness theorem of Gödel constructs a formal-ethical contradiction, i.e., an inconsistency of moral form of activity (Lobovikov 2011b; 2011d; 2014b; 2014c). Being produced in result of consistent deriving logic consequences from a set of precisely formulated nontrivial definitions the equation (32) is very interesting and important one in a wide philosophical context.

I think that the below-submitted equations (33)-(34) make up a model of the rationalists' ideal episteme (a-priori knowledge) which is perfect, i.e., consistent and complete. Hence, knowledge of propositional logic is a-priori one. But the incompleteness theorems of Gödel have demonstrated that the arithmetic theory does not belong to a-priori knowledge system: The theory in question belongs to a-posteriori one.

(33) $T^{R} x y=+=P^{R} x y=+=K_{2} T^{R} x y P^{R} x y$.

(34) $E_{2} T^{R} x y P^{R} x y=+=$ g. $^{7}$

During the long time, there was a popular belief and hope that arithmetic knowledge as a whole is a-priori one. Moreover, among mathematicians and rationalist-minded philosophers, there was a faith and hope that mathematical knowledge as a whole is a-priori one (mathematics is not a science). There was a project to prove the a-priori nature of mathematics as a whole by complete reducing the whole system of mathematics to the arithmetic knowledge (allegedly taken for a-priori one). Gödel's incompleteness theorems crashed that project. But the crash of that project has not refuted the formal-axiological equivalences (33)-(34).

In relation to the above discussion of compositionality, it is worth attracting one's attention to the fact that computing the equations (32), (33), (34) necessarily exploits the above-discussed principle of compositionality of formal-axiological meanings $\left(\mathrm{C}-\mathrm{P}_{2}\right)$. In relation to the above-formulated principle of mutual formal logic autonomy of corresponding facts and contingent values, here it is quite relevant to submit the following discourse exemplifying the logic-autonomy principle by applying it to the specific subject-matter directly related to the main theme of this paper.

In the two-valued algebra of metaphysics as formal ethics of moral rigor, the formal-axiological equation $T^{R} x y=+=P^{R} x y$ deals with moral-value-functions exclusively: It has no formal-logic-entailment relations to corresponding statements of facts. According to the above-given abstract formulation of the principle of logic independence between corresponding facts and accidental values, it is relevant to recognize the following. $\beta T^{R} x y$ stands for the fact-fixing-proposition " $y$ is true for $x$," and $\beta P^{R} x y$ stands for the fact-fixing-proposition " $y$ is provable for $x$." Being propositions (about facts), $\beta T^{R} x y$ and $\beta P^{R} x y$ are either true or false ones. Hence, it is quite natural to connect these two fact-fixing-propositions by the binary logic operation " $\leftrightarrow$ " (logic equivalence). The compound proposition $\beta T^{R} x y \leftrightarrow \beta P^{R} x y$ is nothing but a logic connection of facts: It has 
nothing to do with moral values. According to the above-formulated rule of logic independence of corresponding facts and values, if one implements the following "logic inference," the one commits the blunder, as there is no logic consequence relation between the "premise" and the "corollary."

$$
\frac{T^{R} x y=+=P^{R} x y}{\beta T^{R} x y \leftrightarrow \beta P^{R} x y}
$$

Here committing the jump from the alleged premise to the alleged corollary is strictly forbidden by the above-formulated rule A. Violating this rule can result in a psychologically impressive illusion of logic catastrophe: deriving evidently false purely factual "conclusion" from obviously true purely evaluative "premise." Also the rule A strictly prohibits the converse jump from the factual falsity of $\beta T^{R} x y \leftrightarrow \beta P^{R} x y$ to falsity of $T^{R} x y=+=P^{R} x y$ by "modus tollens" as there is no logic entailment relation between the two substantially different equivalences. Thus, the abstract rule under consideration is exemplified in immediate relation to the main theme of this paper once more.

Also taking into an account the paper title, it is worth looking at the following invalid argument.

$$
\frac{K_{2} K^{E} x y N B^{F} x y=+=K_{2} T^{R} x y N P^{R} x y}{\beta K_{2} K^{E} x y N B^{F} x y \leftrightarrow \beta K_{2} T^{R} x y N P^{R} x y}
$$

I think that being irritated by the "corollary" of this "argument" is a psychologically normal reaction of a normal person. Content analysis of fact-fixing propositions $\beta K_{2} K^{E} x y N B^{F} x y$ and $\beta K_{2} T^{R} x y N P^{R} x y$ shows that their contents are not connected; their logic equivalence is false. But moving from falsity of the "corollary" to falsity of the "premise" (by "modus tollens") is forbidden by the rule A. Thus, the formal-axiological equivalence $K_{2} K^{E} x y N B^{F} x y=+=K_{2} T^{R} x y N P^{R} x y$ is protected from the possible alleged critique based on invalid argument.

\section{Lukasiewicz's Idea of Logic as Morality of Thought and Speech. A Precise Indication of the Status of Formal-Axiological Equivalence between Moore's and Gödel's "Paradoxical" Sentences within the Two-Valued Algebraic System of Formal Ethics Generalizing the Classical Algebraic System of Formal Logic}

According to Jan Lukasiewicz; "Logic is morality of thought and speech" (Woleński 2014). Let us consider logic consequences of accepting this philosophical hypothesis. Ethics deals with morality of any human activity (speaking-and-thinking is a particular case of acting). Consequently, moral-form-of-activity (deprived of its specific contents) is a generalization of logic-form of thought-and-speech (deprived of its specific contents). Consequently, formal ethics is a generalization of formal logic. Hence, there is such a subsystem of system of formal ethics, which completely coincides with the classical two-valued system of formal logic. This basic subsystem of formal ethics is nothing but two-valued system of formal ethics of moral rigor of speaking-and-thinking. The two-valued formal ethics of moral rigor does exist although, evidently, it is neither realistic nor humanistic one. However, here it is important to recognize that the mentioned two-valued formal ethics of moral rigor is a much more universal doctrine than the classical logic. Let us consider the propositional classical logic as an example. Propositions are particular cases of moral actions. Truth-values (true and false) of propositions are particular cases of moral-values (good and bad) of actions, respectively. Hence, the classical two-valued algebraic system of formal logic is a particular case of two-valued algebraic system of formal ethics. Details (definitions, explanations, exemplifications, etc.) concerning this algebraic system of formal ethics can be found in (Lobovikov 1999; 2007b; 2009a; 2009b; 2011a; 2011c; 2014a; 2014c; 
2015b). Here I would like to consider such consequences of the hypothesis in question which are immediately related to the paper theme.

According to the above-given definition DF-1: In two-valued algebra of formal ethics, a moral-evaluation-function (moral activity form) is called formally-ethically (or invariantly) good one (or a law of algebra of formal ethics), if and only if it acquires the moral value $g$ (good) under any possible combination of moral values of its variables.

Consequently, the relationship between notions "formal-logical-law of thought-and-speech" and "formal-ethical-law of human activity in general" can be represented by the following Fig. 2.

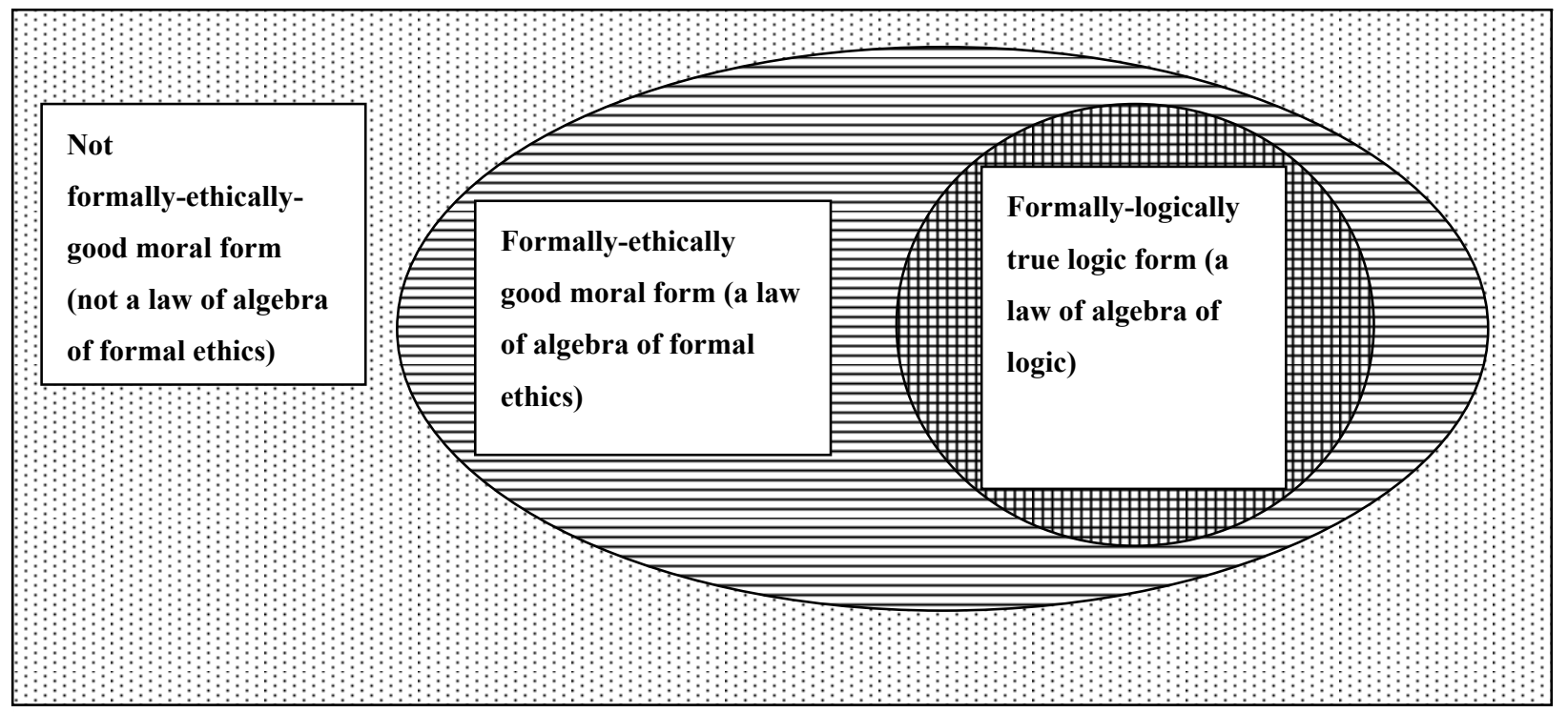

Fig. 2. Relationship between formal-axiological law and formal-logical one.

According to the above-given definition DF-2 (of formal-ethical contradiction): In two-valued algebra of formal ethics, a moral-evaluation-function is called formally-ethically inconsistent (or formally-ethically bad) one, if and only if it acquires the moral value $b(b a d)$ under any possible combination of moral values of its variables.

Consequently, the relationship between formal-logical-inconsistency of thought-and-speech and formal-ethical-inconsistency of activity in general can be represented by the following Fig. 3 .

According to the above-given definition DF-3 (of formal-ethical-equivalence-relation): In two-valued algebraic system of formal ethics, moral-evaluation-functions (moral-forms of human activity) $\Omega$ and $\Psi$ are formally-ethically equivalent (this is represented by the symbol " $\Psi=+=\Omega$ "), if and only if they acquire identical moral values (from the set $\{g(\mathrm{good}), b(\mathrm{bad})\}$ ) under any possible combination of moral values of their moral-evaluation-variables.

Consequently, the relationship between notions "formal-logical-equivalence of logic-forms of thought-and-speech" and "formal-ethical-equivalence of moral-forms of human activity (any one)" can be represented by the following Fig. 4. 




Fig. 3. Status of the sentences of Moore and Gödel.

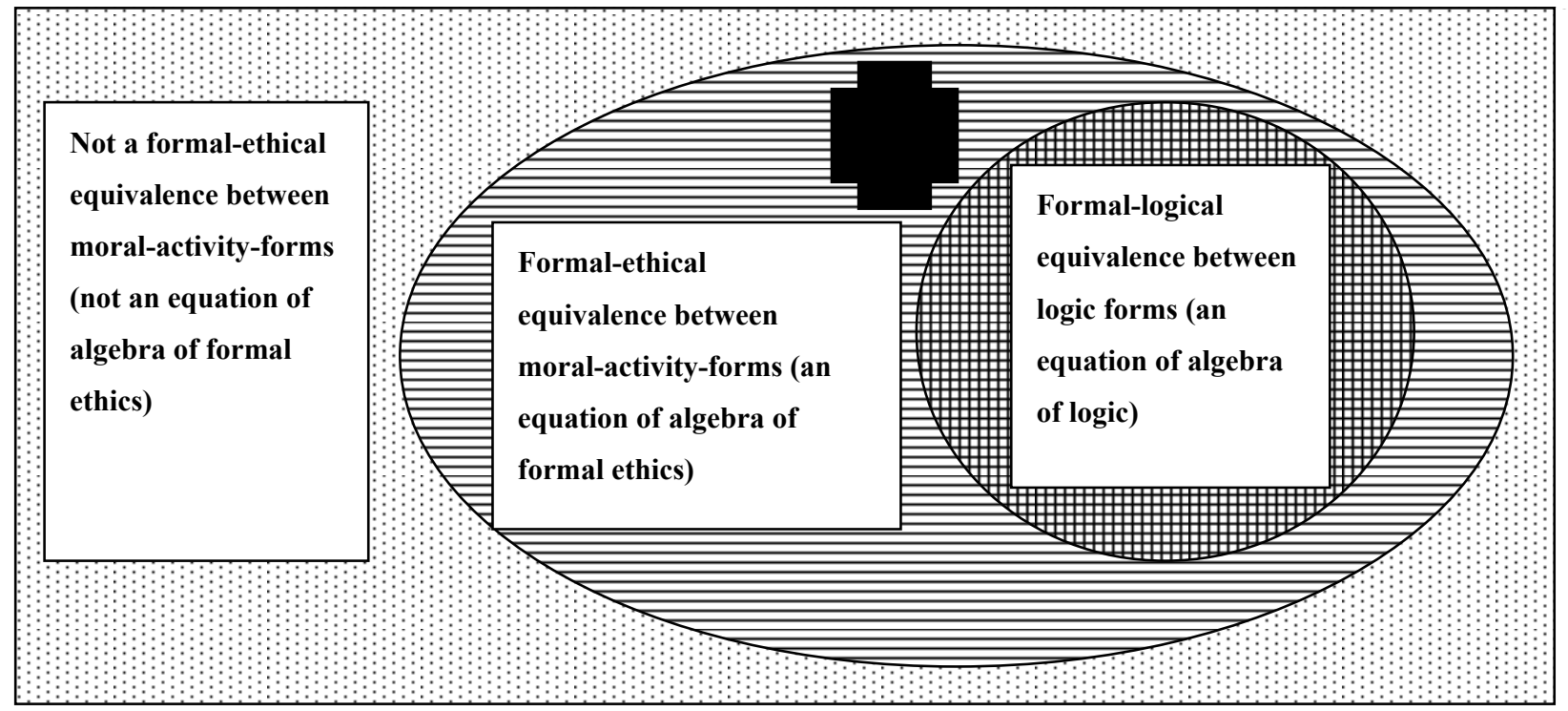

Fig. 4. Status of the formal-ethical equivalence-relation between the sentences of Moore and Gödel.

In the natural language, the formal-ethical equivalence relation " $x=+=y$ " is represented by the ambiguous word-homonym "is." The ambiguity and homonymy of "is" was noticed and recognized by many prominent logicians and philosophers. For adequate understanding the present paper, here it is worthy of note that "is" as the well-known logic connective and "is" as a linguistic means for representing the relation " $x=+=y$ " in the natural language, have significantly different meanings. Hence, substituting them for each other is strictly forbidden. Violating this prohibition produces linguistic illusions of logic contradictions with facts. Using the word "is" at the intersection between formal logic and formal ethics one must be careful.

Now being equipped with the above-submitted formal-ethical apparatus, let us discuss the formal-ethical equivalence-relation between the incompleteness theorem of Gödel and the epistemic paradox of Moore. In this 
paper, I mean the first Gödel's theorem of incompleteness of formal arithmetic theory. In purely-mathematical-logic relation, the theorem is not questioned: It is recognized as a perfectly proved one. The epistemic paradox of Moore is recognized as a formally-logically consistent sentence containing no formal-logical self-contradiction of thought and speech. However, in this paper for the first time in world literature, the two notorious sentences under comparison are manifestly evaluated and strictly demonstrated as formally-ethically equivalent ones within the framework of the two-valued algebra of formal ethics of moral rigor. The novel and psychologically surprising statement of such a formal-ethical-equivalence is a logical consequence of conjunction of the two papers (Lobovikov 2011d; 2014b). Another option: the statement logically follows from the conjunction of papers (Lobovikov 2009b; 2011b; 2014b). Also the conjunction of papers (Lobovikov 2009b; 2011b; 2014c) logically entails the formal-ethical-equivalence of the two sentences under consideration. Nevertheless, hitherto their formal-ethical-equivalence was neither recognized nor manifestly formulated: The last step (move) towards the discovery was not done. In the present paper, the surprising equivalence is discovered, recognized, substantiated, and submitted for the first time.

Using graphic means, the main new idea of this paper is modeled by the above Figs. 3 and 4 in which the black triangle stands for the sentence of Moore, the black star stands for the sentence of Gödel, and the black cross stands for the formal-ethical equivalence-relation between the sentences of Moore and Gödel. Both sentences are formally-logically consistent but they belong to one and the same class of formally-ethically inconsistent moral-activity-forms. Hence, there is a formal-ethical-equivalence relation between the two sentences under comparison.

\section{Notes}

1. Beginning of the paper is my compilation of some of my works (Lobovikov 2009b; 2011b; 2011d; 2014a; 2014b; 2014c; 2015b). Placing this compilation at the beginning of the present paper is indispensable for adequate understanding such a significantly new nontrivial result submitted in this paper which is still not published elsewhere. The paper's main novel statement of the surprising fact of the hitherto unknown nontrivial formal equivalence mentioned in the title is still not published. (It was orally presented by me in English at the II Colombian Congress of Logic, Epistemology and Philosophy of Science. February 8-10, 2012, Universidad de los Andes, Bogotá, Colombia, in my paper titled 'From Logicism to 'Ethicism' in the Philosophy of Mathematics: From the Formal Logic of Thinking to the Formal Ethics of Acting," but, unfortunately, there was no printed handbook of the conference materials. Only the program was available. The present paper is a further developed complete text of that oral presentation in Bogotá.)

2. This model follows Wittgenstein's worldview and develops it further: Hence, the model under discussion here is the one of Wittgenstein's opinion. In my own opinion, a contingent coincidence between fact and contingent (factual) value is possible: Only necessary (absolute) moral values are excluded from the set of facts.

3. According to Leibniz, truths are either necessary or factual (accidental) ones. As by Wittgenstein's definition, the world $\mathrm{W}_{1}$ is a totality of facts; the necessary and the impossible states of affairs do not exist in $\mathrm{W}_{1}$. Hence, in the language $\mathrm{L}_{1}$ (which is isomorphic to the world $\mathrm{W}_{1}$ ) the sentences about either-necessary-or-impossible states of affairs (i.e., either-tautologies-or-logic-contradictions, respectively) are meaningless. This note successfully explains Wittgenstein's enigmatic treating tautologies as semantic nonsenses. However, if within the scope of classical two-valued logic one possessing commonsense defines semantic nonsenses as neither true nor false statements, then tautologies are not semantic nonsenses. That is why very often the one possessing commonsense is puzzled by Wittgenstein's surprising consideration of tautologies as semantic nonsenses.

4. In spite of the dominating belief that the (fact-\&-accidental-value)-separation principle under explication is necessarily universal one, I think that it is not so. I believe that the relevant-applicability domain of the separation principle is necessarily restricted: Its complement is not empty one. In my opinion, the principle's domain is necessarily reduced to the realm of facts and factual (accidental) evaluations. Necessarily positive and necessarily negative moral evaluations do not belong to this realm. Hence, in my opinion, it is irrelevant to apply the separation principle to the relationship between tautological statements of necessarily universal being (absolute being) and ones of necessarily universal moral value (absolute goodness). Such irrelevant applying is committing a blunder heading to hard confusions in worldview discussions. 
5. Part 4, Book 11, Chapter 4 (“A Hymn and a Secret”) of the novel (Dostoyevsky 2011).

6. I presented this picture at the international conference (2015c).

7. Originally the equations (33)-(34) were published in my papers (2009b; 2009c).

\section{Works Cited}

Almeida, Claudio de. "What Moore's Paradox Is about?" Philosophy \& Phenomenological Research 62 (2001): 33-58.

Béziau, Jean-Yves. "What Is Paraconsistent Logic?” Frontiers of Paraconsistent Logic. Baldock: Research Studies Press, 1999. 95-112.

---. "The New Rising of the Square of Opposition." Eds. Jean-Yves Beziau and Dale Jacquette. Around and beyond the Square of Opposition. Basel: Birkhäuser, 2012a. 3-19.

---. "The Power of the Haxagon." Universal Logic 6 (2012b): 1-43.

Béziau, Jean-Yves, and Stephen Read. Special Issue of History and Philosophy of Logic on the History of the Square of Opposition 35.4 (2014).

Blanché, Robert. "On the Structure of the Table of Binary Inter-Propositional Connectives.” Journal of Symbolic Logic 22 (1957): $17-18$.

---. Intellectual Structures. Essay on Systematical Organization of Concepts. Paris: Vrin, 1966.

---. "On the System of Inter-Propositional Connectives." Analysis Notebooks 10 (1969): 131-49.

Cholbi, Michael. "Moore's Paradox and Moral Motivation." Ethical Theory \& Moral Practice 12 (2009): 495-510.

Correia, Manuel. "The Syllogistic Theory of Boethius." Ancient Philosophy 29 (2009): 391-405.

---. "Boetius on the Square of Opposition." Eds. Jean-Yves Beziau and Dale Jacquette. Around and beyond the Square of Oppositon. Basel: Birkhäuser, 2012. 41-52.

Costa, Newton da. "On the Theory of Inconsistent Formal Systems.” Notre Dame Journal of Formal Logic 15 (1974): $497-510$.

Costa, Newton da, Décio Krause, and Otávio Bueno. "Paraconsistent Logics and Paraconsistency." Ed. Dale Jacquette. Philosophy of Logic (Handbook of the Philosophy of Science). Amsterdam: North-Holland Publishing Co., 2007. 791-912.

Deangelis, William James. Ludwig Wittgenstein-A Cultural Point of View. Boston: Northeastern University, 2007.

Dostoyevsky, Fyodor. The Brothers Karamazov. Escondido: Mission Books/eChristian, Inc., 2011.

Dufatanye, Aimable-André. "From the Logical Square to Blanché's Hexagon: Formalization, Applicability and the Idea of the Normative Structure of Thought." Universal Logic 6 (2012): 45-67.

Goldstein, Laurence. Clear and Queer Thinking: Wittgenstein's Development and His Relevance to Modern Thought. London: Duckworth, 1999.

Green, Mitchel, and John Williams. Moore's Paradox: New Essays on Belief, Rationality and the First-Person. Oxford: Clarendon Press; New York: Oxford University Press, 2007.

---. "Moore's Paradox, Truth and Accuracy." Analytic Acts 26 (2011): 243-55.

Hacker, Peter. Wittgenstein's Place in Twentieth Century Analytic Philosophy. Oxford: Blackwell, 1996.

Guthrie, William Keith Chambers. A History of Greek Philosophy. Vol. 2: The Presocratic Tradition from Parmenides to Democritus. Cambridge: University Press, 1990.

Heal, Jane. "Moore's Paradox: A Wittgensteinian Approach.” Mind 103 (1994): 5-23.

Horwich, Paul. "The Composition of Meanings." Philosophical Review 106 (1997): 503-33.

Jareño-Alarcón, Joaquín. Religion and Relativism in Wittgenstein. Barcelona: Ariel, 2001.

Kalinowski, Georges. Logic of Norms. Paris: Presses Universitaires de France, 1972.

Lobovikov, Vladimir. Mathematical Jurisprudence and Mathematical Ethics. Yekaterinburg: The Urals State University Press; Ural State Law Academy Press; Liberal Arts University Press, 1999.

---. "Aristotelian and Juridical Modalities: A New Theory of Their Unity (A Two-Valued Algebra of Formal Natural-Law Philosophy of Modalities as Moral-Legal Evaluation-Functions Determined by Two Variables-A Complement to G. H. Wright's Deontic Logic Interpretation of G. W. Leibniz's Idea about the Unity of the Two Kinds of Modalities)." Brazilian Legal Theory Review—RFDCL (Revista da Faculdade de Direito de Conselheiro Lafaiete) 3 (2007a): 181-7.

---. Mathematical Ethics, Metaphysics and the Natural Law (Algebra of Metaphysics as Algebra of Formal Axiology). Yekaterinburg: The Institute of Philosophy and Law of the Ural Branch of RAS, 2007b. 
---. "Mathematical Logic as a Particular Case of Mathematical Ethics (Algebra of Formal Ethics as a Generalization of Algebra of Formal Logic)." Eds. Costas Drossos, Pavlos Peppas, and Constantine Tsinakis. Proceedings of the 7th Panhellenic Logic Symposium (PLS7) at Patras University, Greece, July 15-19, 2009. Patras: Patras University Press, 2009a. 109-11.

---. "Mathematical Simulating Formal Axiological Semantics of Natural Languages (A Fundamental Generalization of Mathematical Philosophy: From Truth-Values to Axiological Ones)." Philosophy, Mathematics, Linguistics: Aspects of Interconnection: Proceedings of the International Scientific Conference (November 20-22, 2009, Sankt-Petersburg, L. Euler International Mathematical Institute). St.-Petersburg: VVM, 2009b. 128-32.

---. 'K. Gödel's Incompleteness Theorems and a Hitherto Unknown Non-trivial Formal Equivalence of 'True' and 'Provable."' Collection of Abstracts of International Conference "MAL'TSEV MEETING" Dedicated to the 100th Anniversary of Anatolii Ivanovich Mal'sev (Sobolev Institute of Mathematics, Novosibirsk State University, August 24-28, 2009). Novosibirsk: Sobolev Institute of Mathematics, 2009c, 220.

---. "Discrete Mathematical Representing G. W. Leibniz' Philosophy of Law, Morals and Theology by Means of Two-Valued Algebra of the Natural Law (Studying Moral-legal Evaluation-Functions Determined by Two Variables in Algebra of Formal Axiology)." Eds. Herbet Breger, Jürgen Herbst, and Sven Erdner. XI International Leibniz-Congress "Nature and Subject" under the Auspices of Federal President (Hannover, 26 September until 1 October 2011), Vol. 2. Berlin: Akademie Verlag; Bahlsen GmbH \& Co. KG, 2011a. 611-5.

---. "A Proof of a Formal-Axiological Inconsistency of the Formal Arithmetic Investigated by K. Gödel (the Proof Essentially Using Own Axioms of Formal Axiology).” Ed. Vladimir Ilyich Markin. The 7th Smirnov Readings in Logic: Proceedings of the International Scientific Conference. Moscow: Contemporary Copybooks, 2011b. 92-93.

--- "Discrete Mathematical Representing the Value of Knowledge.” Eds. Christoph Jager and Winfried Loffler. Epistemology: Contexts, Values, Disagreement. Papers of the 34th International Wittgenstein Symposium (August 7-13, 2011, Kirchberg am Wechsel, Lower Austria). Contributions of the Austrian Ludwig Wittgenstein Society, Vol. XIX. Kirchberg am Wechsel: Austrian Ludwig Wittgenstein Society, 2011c. 175-7.

---. "Logic-Philosophic Substantiating a Hypothesis about a Formal-Ethical Inconsistency of the Formal Arithmetic Investigated by K. Gödel.” IZVESTIA-Ural Federal University Journal. Series 3: Social and Political Sciences 88.1 (2011d): 14-28.

---. "Algebra of Morality and Formal Ethics." Ed. Katarzyna Bronk. Looking Back to See the Future: Reflections on Sins and Virtues. Oxford: Inter-Disciplinary Press, 2014a. 17-41.

---. "Moore's Paradox in the Light of Algebra of Formal Ethics." IZVESTIA-Ural Federal University Journal. Series 3: Social and Political Sciences 125.1 (2014b): 44-56.

---. "Squares and Hexagons of Formal-Ethical Opposition in Two-Valued Algebra of Formal Ethics. An Algebraic System of Moral-Evaluation-Functions: 'Being', 'Knowing', 'Faith', 'Love', et al.' Aporia-International Review of Philosophical Investigations/Santiago de Chile 8 (2014c): 4-22.

---. “'Fear', 'Horror' and 'Terror': Not Moral-Evaluation Constants but Moral-Evaluation Functions Determined by Two Moral-Evaluation Variables in Algebra of Formal Ethics.” Eds. Laura Colmenero-Chilberg and Ferenc Mújdricza. Facing Our Darkness: Manifestations of Fear, Horror and Terror. Oxford: Inter-Disciplinary Press, 2015a. 193-203.

---. "The Trinity Triangle and the Homonymy of the Word 'Is' in Natural Language (A Logically Consistent Discrete Mathematical Representation of the Trinity by Means of Algebra of Morality and Formal Ethics)." Philosophy Study 5.7 (2015b): 327-41. (doi: 10.17265/2159-5313/2015.07.001)

---. “A Meta-theoretical Interpretation of the Logical Square and Hexagon of Opposition.” Eds. Jean-Yves Beziau, Safak Ural, Arthur Buchsbaum, Iskender Tasdelen, and Vedat Kamer. Handbook of the 5th World Congress and School on Universal Logic (June 20-30, 2015, Istanbul, Turkey). Istambul: University of Istambul, 2015c. 346-8.

Malcolm, Norman, and Peter Winch. Wittgenstein: A Religious Point of View? London: Routledge, 1993.

Moretti, Alessio. "Why the Logical Hexagon?” Universal Logic 6 (2012): 69-107.

Pagin, Peter. "Communication and Strong Compositionality." Journal of Philosophical Logic 32 (2003): 287-322.

Pelletier, Francis Jeffry. "The Principle of Semantic Compositionality.” Topoi 13 (1994): 11-24.

---. “Did Frege Believe in Frege's Principle?” Journal of Logic, Language, and Information 10 (2001): 87-114.

---. "Context-Dependence and Compositionality." Mind and Language 18 (2003): 148-61.

Sesmat, Augustin. Logic II. Reasoning, the Logistics. Paris: Hermann, 1951.

Werning, Markus, Wolfram Hinzen, and Edouard Machery, ed. Oxford Handbook of Compositionality. Oxford: Oxford University Press, 2012.

Wittgenstein, Ludwig. Treatise Logical-Philosophical. London: Routledge and K. Paul, 1949. 
---. Notebooks 1914-1916. Oxford: Blackwell, 1961.

---. Lectures and Conversations on Aesthetics, Psychology and Religious Belief. Oxford: Basil Blackwell, 1966.

---. "A Lecture on Ethics." Eds. James Klagge and Alfred Nordmann. Philosophical Occasions (1912-1951). Indianapolis: Hackett, 1993. 36-44.

Woleński, Jan. "Lvov-Warsaw School." Eds. Edward Zalta. The Stanford Encyclopedia of Philosophy (Spring 2014 Edition). $<$ http://plato.stanford.edu/archives/spr2014/entries/lvov-warsaw/>.

Wright, Georg Henrik. Wittgenstein. Minneapolis: University of Minneapolis Press, 1982. 